\title{
Molecular Imaging of Cardiovascular Device Infection: Targeting the Bacteria or the Host-Pathogen Immune Response?
}

\author{
Wengen Chen and Vasken Dilsizian \\ Department of Diagnostic Radiology and Nuclear Medicine, University of Maryland School of Medicine, Baltimore, Maryland
}

\begin{abstract}
Learning Objectives: On successful completion of this activity, participants should be able to (1) understand the role of $18 \mathrm{~F}-\mathrm{FDG}$ PET/CT for diagnosis of cardiovascular device infection, as a functional imaging tool for assessing the overall host-pathogen immune response in infection; (2) learn about the strengths and limitations of bacteria-targeting radiotracers for infection imaging, including those based on substances of bacterial maltodextrin transporters, bacterial thymidine kinase, antibiotics, antimicrobial peptides, antibacterial antibodies, bacteriophages, and bacterial DNA/RNA hybrid nucleotide oligomers; and (3) discuss the pros and cons of ${ }^{18}$ F-FDG versus bacteria-targeting tracers.
\end{abstract}

Financial Disclosure: The authors of this article have indicated no relevant relationships that could be perceived as a real or apparent conflict of interest.

CME Credit: SNMMI is accredited by the Accreditation Council for Continuing Medical Education (ACCME) to sponsor continuing education for physicians. SNMMI designates each JNM continuing education article for a maximum of 2.0 AMA PRA Category 1 Credits. Physicians should claim only credit commensurate with the extent of their participation in the activity. For CE credit, SAM, and other credit types, participants can access this activity through the SNMMI website (http://www.snmmilearningcenter.org) through March 2023.

Rapid and accurate diagnosis of cardiovascular device infection remains a challenge in the clinic. Anatomic imaging tools such as echocardiography and cardiac CT or CT angiography are the firstline modalities for clinically suspected endocarditis given their ability to detect vegetation and perivalvular complications. Accumulating data suggest that functional imaging with ${ }^{18} \mathrm{~F}-\mathrm{FDG}$ PET/CT has unique merits over anatomic imaging and could potentially diagnose early cardiac device infection before morphologic damage ensues and identify infection sources or bacterial emboli in the rest of the body. Although an abnormal finding on ${ }^{18} \mathrm{~F}-\mathrm{FDG}$ PET/CT was added to the 2015 guidelines of the European Society of Cardiology as a major criterion for the diagnosis of device-related and prosthetic valve endocarditis, that addition has not been incorporated in the U.S. guidelines. Beyond these clinically available imaging tools, attempts have been made to develop bacteria-targeting tracers for specific infection imaging, which include tracers of bacterial maltodextrin transporter, bacterial thymidine kinase, antibiotics, antimicrobial peptides, bacterial antibodies, bacteriophages, and bacterial DNA/RNA hybrid nucleotide oligomers. Most of the tracers have been studied only in experimental animals, except for radiolabeled antibiotics, which have been examined in humans without success in clinical translation for infection imaging. In this article, we compare the roles of anatomic and functional imaging for cardiac device infection and discuss the pros and cons of ${ }^{18} \mathrm{~F}-\mathrm{FDG}$ and bacteria-targeting tracers. While anticipating continued investigations for bacteria-specific tracers in the future, we recommend that ${ }^{18} \mathrm{~F}-\mathrm{FDG} \mathrm{PET} / \mathrm{CT}$, which represents the host-pathogen immune response to infection, be used clinically for identifying cardiovascular device infection.

Received Nov. 12, 2019; revision accepted Jan. 22, 2020.

For correspondence or reprints contact: Wengen Chen, Department of Diagnostic Radiology and Nuclear Medicine, University of Maryland Medical Center, 22 S. Greene St., Room N2W78, Baltimore, MD 21201.

E-mail: wchen5@umm.edu

Published online Feb. 7, 2020

COPYRIGHT (C 2020 by the Society of Nuclear Medicine and Molecular Imaging.
Key Words: FDG; PET/CT; bacteria; infection; maltodextrin transporter; cardiovascular device

J Nucl Med 2020; 61:319-326

DOI: $10.2967 /$ jnumed.119.228304

\section{B} acterial infection remains a worldwide health problem associated with major mortality and morbidity, yet it is treatable if diagnosed at an early stage. Patients with implanted medical devices, such as electronic or prosthetic cardiac devices, are prone to infection because of their older age and underlying comorbidities $(1,2)$. There has been a continuous increase in the implantation of cardiovascular devices such as pacemakers, defibrillators, prosthetic valves, and left ventricular assist devices (3). Infection is one of the major complications of device implantation, often progresses quickly, and is potentially life-threatening if not diagnosed and treated early (4). On the other hand, overdiagnosis of infection often leads to unnecessary extraction and reimplantation of the device and the associated increase in hospital stays and mortality, imposing a substantial societal and medical burden. Thus, accurate and rapid diagnosis of infected cardiovascular devices is critical for patient management and therapeutic decisions. Clinical diagnosis of cardiac device infection, particularly device-related endocarditis, involves a multidisciplinary team that includes a cardiologist, an infectious disease physician, a microbiology specialist, and imaging specialists (5). Imaging tools play a vital role in localizing and diagnosing cardiovascular device infection and in monitoring treatment response. These tools include anatomically based modalities such as transthoracic echocardiography or transesophageal echocardiography (TEE), electrocardiography-gated cardiac CT or CT angiography (CTA), and functionally based modalities-mainly radionuclide imaging with ${ }^{18} \mathrm{~F}-\mathrm{FDG}$ PET/CT and ${ }^{111} \mathrm{In}-$ or ${ }^{99 \mathrm{~m}} \mathrm{Tc}-$ labeled autologous white blood cell (WBC) SPECT/CT. These imaging modalities visualize and diagnose infection on the basis of morphologic and functional changes in the host inflammatory 
immune response to the infectious pathogens. In this article, we examine the roles of these anatomically based (TEE, CT) and functionally based (PET/CT, WBC scan) imaging tools for diagnosing cardiac device infection and discuss the pros and cons of other investigational imaging strategies, such as bacteria-targeted imaging. On the basis of the overall body of articles published, we propose judicious implementation of ${ }^{18} \mathrm{~F}$-FDG PET/CT for evaluating cardiac device infection.

\section{ANATOMIC IMAGING TOOLS}

Anatomically based imaging tools are frequently used in diagnosing cardiovascular device infection. Echocardiography and cardiac CT/CTA are currently the first-line imaging studies for devicerelated and prosthetic valve endocarditis diagnosis, recommended in the 2014 guideline of the American Heart Association/American College of Cardiology ( 6 ) and the 2015 guideline of the European Society for Cardiology (7). Results of the recent European Infectious Endocarditis Registry showed that $99.8 \%$ of the patients received echocardiography, with TEE being more frequently used in prosthetic valve endocarditis patients (8). Abnormal findings on echocardiography as a major criterion were present in $89.1 \%$ of the patients (8). Echocardiography, particularly TEE, can detect valvular vegetation and can also assess perivalvular complications (perforation, pseudoaneurysm, fistulas, and valve dehiscence) with acceptable accuracy (9). TEE findings may also predict embolic events (10). However, TEE may miss up to $30 \%$ of valvular prosthetic endocarditis because of the underlying metal ring-related acoustic shadowing artifact (11). Cardiac CT/ CTA is a modality of choice for assessing perivalvular complications with a high sensitivity, better than TEE (12). However, both modalities detect late morphologic changes of infection, and findings are often nonspecific and associated with artifacts from the device's foreign material components. TEE is limited to the intracardiac device components and is not able to assess other parts of the device or even the right side of the heart. Although CT can assess infection in the cardiac implantable electronic device pocket and leads, it is not able to evaluate the rest of the body for potential sources of infection or sites of infectious embolism, which are critical for clinical management. Thus, functional ${ }^{18} \mathrm{~F}-\mathrm{FDG}$ PET/ CT and radiolabeled WBC scans have been used and studied for their roles in improving the diagnosis of cardiac device infection. In addition, other strategies such as bacteria-targeting tracers are under active study in experimental animals for their potential translation to the clinic.

\section{FUNCTIONAL IMAGING TOOLS}

${ }^{18} \mathrm{~F}-\mathrm{FDG}$ PET/CT and ${ }^{111} \mathrm{In}$ - or ${ }^{99 \mathrm{~m}} \mathrm{Tc}-$-labeled WBC SPECT/CT are useful functional imaging techniques for the diagnosis of cardiac device infection. Abnormal findings on ${ }^{18} \mathrm{~F}$-FDG PET/CT or WBC scans have been added as a major imaging criterion for the diagnosis of endocarditis in the European Society for Cardiology guideline though not yet in U.S. guidelines (7). Accumulating data have suggested that ${ }^{18} \mathrm{~F}-\mathrm{FDG} \mathrm{PET} / \mathrm{CT}$ could have several merits over TEE and CTA in assessing cardiovascular device infection given its functional and whole-body imaging nature. One merit is the ability to diagnose infection earlier, before TEE- and CTAdetectable morphologic damage ensues. Another is the ability to provide metabolic evidence for a confirmatory diagnosis when TEE and CTA findings are inconclusive or equivocal. A third merit is the ability to diagnose infection in the extracardiac parts of a device, such as the pacemaker/defibrillator pocket and lead, or the driveline of a left ventricular assist device, which is beyond the TEE and CTA views. A final merit of ${ }^{18} \mathrm{~F}-\mathrm{FDG}$ PET/CT is the ability to image extracardiac portions of the body in the search for a primary infection source or infectious emboli $(13,14)$. Figure 1 shows 3 examples of infections-in a cardiac implantable electronic device pocket, a prosthetic valve, and a left ventricular assist device-as seen on ${ }^{18} \mathrm{~F}$-FDG PET/CT. A systematic review showed a sensitivity of $73 \%-100 \%$ and a specificity of $71 \%-100 \%$ for ${ }^{18} \mathrm{~F}$-FDG PET/CT in the diagnosis of infection in the pocket of a cardiac implantable electronic device (15). A second metaanalysis showed similar results, with a pooled sensitivity of $87 \%$ and specificity of $94 \%$ (16). For device-related or prosthetic endocarditis diagnosis, it has been shown that adding ${ }^{18}$ F-FDG PET/CTpositive findings as a major criterion to the modified Duke criteria increased diagnosis sensitivity from $52 \%-70 \%$ to $91 \%-97 \%$ without compromising specificity $(17,18) .{ }^{18} \mathrm{~F}-\mathrm{FDG}$ PET/CT may change management in up to $35 \%$ of clinically suspected endocarditis cases (19). For left ventricular assist device infections, it has been shown that in addition to being able to accurately localize the site and extent of infection along the driveline or central portion of the left ventricular assist device (20), ${ }^{18}$ F-FDG PET/CT can predict clinical progress and outcome better than CT can (Fig. 2) (21). WBC SPECT/CT is less sensitive for device infection but is more specific than ${ }^{18} \mathrm{~F}$-FDG PET/CT (22), and sequential ${ }^{18} \mathrm{~F}-\mathrm{FDG}$ $\mathrm{PET} / \mathrm{CT}$ and WBC scans have been shown to provide a more accurate diagnosis for cardiovascular device infection (23). However, clinical use of ${ }^{18} \mathrm{~F}-\mathrm{FDG}$ PET/CT is low in the workup of cardiac device infection. For example, the European Infectious Endocarditis Registry data showed that ${ }^{18} \mathrm{~F}$-FDG PET/CT was performed on only $16.6 \%$ of patients, with a better sensitivity in prosthetic valve endocarditis $(62.5 \%)$ than in native $(28.0 \%)$ and device-related endocarditis $(16.3 \%)(8)$. The use of ${ }^{18} \mathrm{~F}$-FDG PET/CT in the United States to image cardiac device infection is probably even lower, as such use has not been endorsed in the U.S. guidelines and is not currently reimbursed for infection or inflammation imaging. Although most of the studies using ${ }^{18} \mathrm{~F}-\mathrm{FDG}$ PET/CT for cardiac device infection are retrospective, current clinical practice and expert consensus support the judicious use of ${ }^{18} \mathrm{~F}$-FDG PET/CT in the workup of cardiovascular device infection $(24,25)$.

Table 1 compares anatomic (TEE and CT/CTA) and functional ( ${ }^{18}$ F-FDG PET/CT, WBC scanning) imaging modalities for evaluation of cardiovascular device infection.

\section{BACTERIA-TARGETING TRACERS}

In an effort to specifically image bacterial infection, attempts have been made to develop tracers that directly target bacterial pathogens in a suspected infection site, which include bacterial metabolic substances (e.g., carbohydrates and nucleosides), antibiotics, antimicrobial peptides, bacterial antibodies, bacteriophages, and bacterial DNA/RNA hybrid nucleotide oligomers. Among these classes of tracers, radiolabeled antibiotics, particularly ${ }^{99 \mathrm{~m} T c-c i p r o f l o x a c i n}$, have been extensively studied in clinical trials, without success for clinical translation. Others, such as maltodextrin-based tracers, are still mainly in experimental stages of investigation, with variable clinical promise.

\section{Bacterial Metabolic Substances}

Carbohydrates. Different from glucose (and its ${ }^{18} \mathrm{~F}$-labeled analog of FDG), which can be used by both mammalian cells and microbes, certain types of polysaccharides such as maltodextrins can be taken 


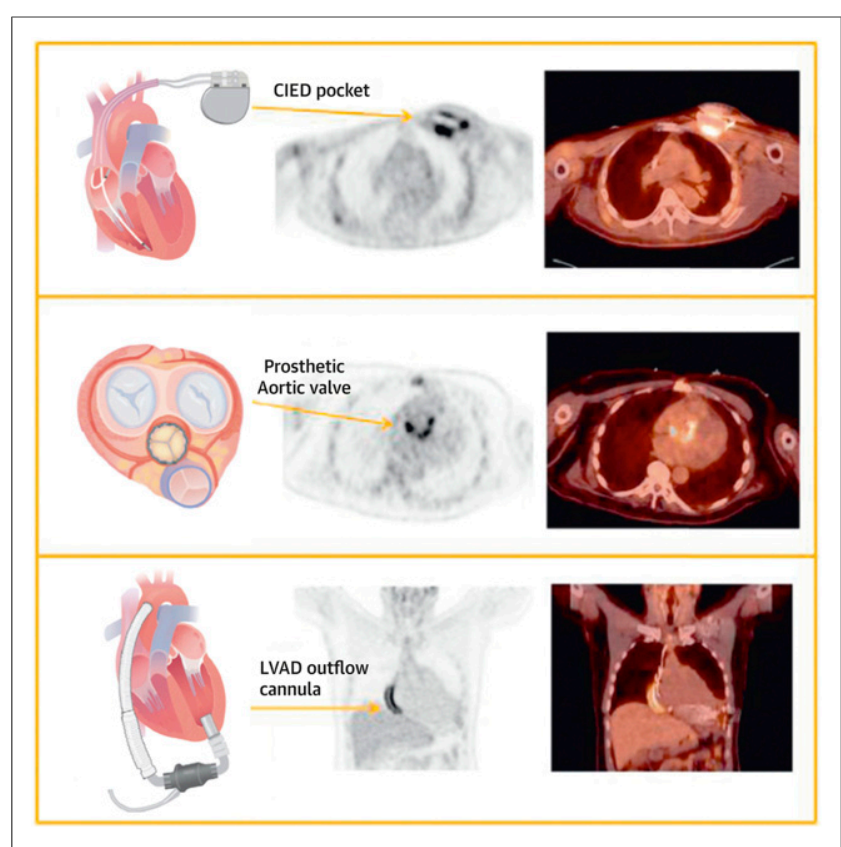

FIGURE 1. Examples of cardiac device infections: illustration of devices (left), PET scans (middle), and ${ }^{18}$ F-FDG PET/CT scans. (Top) Cardiac implantable electronic device (CIED). There is intense ${ }^{18} \mathrm{~F}-\mathrm{FDG}$ uptake beneath left upper chest wall CIED pocket, compatible with deep pocket infection. (Middle) Cardiac prosthetic valve. There is intense ${ }^{18} \mathrm{~F}-\mathrm{FDG}$ uptake along prosthetic aortic valve, compatible with prosthetic valve endocarditis. (Bottom) Left ventricular assist device (LVAD). There is intense ${ }^{18} \mathrm{~F}-\mathrm{FDG}$ uptake along outflow cannula of LVAD in mediastinum, compatible with central LVAD infection. (Reproduced with permission of (14).)

up and used only by bacteria via maltodextrin transporter (26). Maltodextrin transporter belongs to a family of adenosine triphosphatebinding cassette transporters, which is expressed only in bacteria, not in mammalian cells (26), making it an attractive target for specific bacterial infection imaging. Bacterial maltodextrin transporter can transport maltodextrins with glucose units from 2 (maltose) up to 7 (maltoheptaose) (27). The nonreducing end of a maltodextrin is required for initial binding to the transporter, whereas the reducing end is required for intrabacterial transport (28). Labeling can be performed at the reducing end because bacterial maltodextrin transporters can generally tolerate structure modifications and substitutions at the reducing end (29). Meanwhile, both the nonreducing and the reducing ends of maltodextrins are susceptible to degradation by plasma $\alpha$-glucosidase and $\alpha$-amylase, respectively (29), which can result in low tracer stability in the blood with a short imaging window. This restriction should be considered when a maltodextrin-based tracer is being designed for imaging. Certain types of maltodextrin, for example, maltotriose, have been found to be natively resistant to the $\alpha$-amylase, whereas others, such as maltopentaose, are quickly degraded by the enzyme (29).

Different types of fluorescence- and ${ }^{18} \mathrm{~F}$-labeled maltodextrin tracers have been synthesized and tested on animals for their potential clinical translation for bacteria-specific infection imaging. These tracers include fluorescence-maltohexaose (30), ${ }^{18} \mathrm{~F}$-maltohexaose (31), ${ }^{18} \mathrm{~F}$-maltose (32), ${ }^{18} \mathrm{~F}$-maltotriose (33), ${ }^{18} \mathrm{~F}$-sorbitol (34), and ${ }^{18} \mathrm{~F}$ trehalose (35).

Work in this field was initiated by Ning et al., who first synthesized fluorescence- and ${ }^{18} \mathrm{~F}$-labeled maltohexaose for optical and PET imaging of bacterial infection, respectively $(30,31)$. Both tracers could visualize bacterial infection in rat thigh, with very low activity in the contralateral thigh with lipopolysaccharide-induced inflammation, indicating potential to distinguish between bacterial infection and sterile inflammation. A subsequent study of cardiac pocket infection in a rat model showed that both tracers accumulated in the cardiac pocket infection sites but not in sterile inflammation sites induced by turpentine oil. In contrast, ${ }^{18} \mathrm{~F}-\mathrm{FDG}$ uptake was observed in both the infection and the inflammation sites (Fig. 3) (36). ${ }^{18} \mathrm{~F}$-maltohexaose uptake could also be detected in a biofilm model, indicating its potential use for biofilm infection (36). The fluorescence tracer was found mainly in the liver, with very low counts in the kidneys, indicating its primary hepatobiliary excretion (36). Although ${ }^{18} \mathrm{~F}-$ maltohexaose showed significant excretion in the urine at early time points (36), the stability of the fluorescenceand ${ }^{18} \mathrm{~F}$-maltohexaose tracers in the blood was not reported. In addition to having different plasma amylase activities, humans and rats may also have different tracer pharmacokinetics. To our knowledge, no clinical human studies with these 2 tracers have yet been reported.

A new tracer, ${ }^{18} \mathrm{~F}$-labeled maltotriose, was recently shown to have a superior pharmacokinetic feature for infection imaging, with urinary clearance (33). Mouse PET imaging showed that ${ }^{18} \mathrm{~F}$-maltotriose accumulated in bacteria-induced muscle infection but not in lipopolysaccharide-induced inflammation, indicating its specificity for bacterial infection. Although maltotriose has previously been shown to be natively resistant to $\alpha$-amylase (29), ${ }^{18} \mathrm{~F}$ maltotriose stability in the blood was not reported, and a human study is also lacking.

In addition to the above-mentioned tracers, other maltodextrinbased tracers have also been developed and tested on animal models, but with certain limitations. For example, ${ }^{18} \mathrm{~F}$-maltose can also accumulate in inflammation sites, raising concerns of nonspecificity (32). The radio-pharmacokinetics of the ${ }^{18} \mathrm{~F}$-maltose tracer was suboptimal, with predominant hepatic excretion. Another tracer, ${ }^{18} \mathrm{~F}$ sorbitol, can target only gram-negative Enterobacteriaceae-specific infection, as sorbitol can be metabolized only by gram-negative

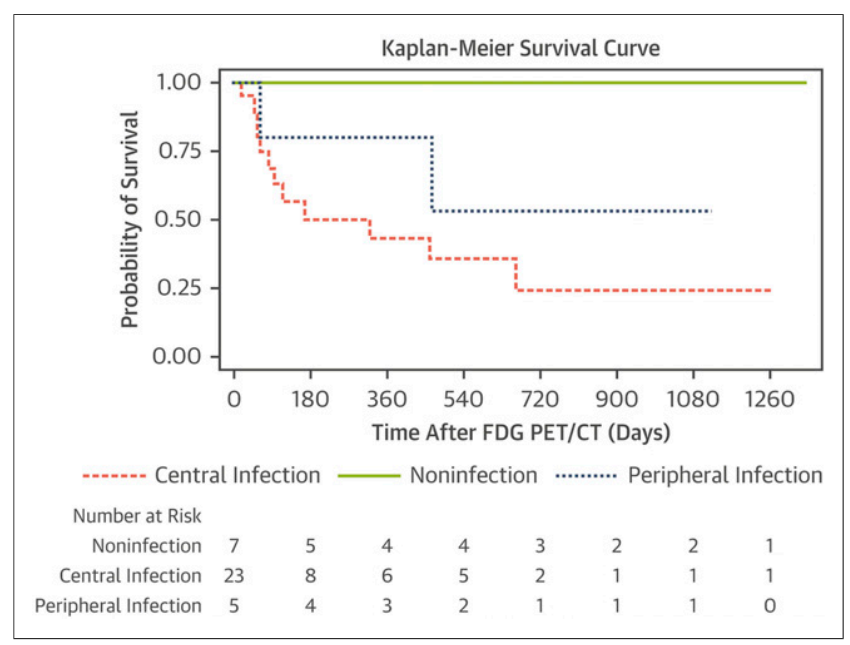

FIGURE 2. Kaplan-Meier survival curves in patients with left ventricular assist device (LVAD). Patients are grouped according to noninfection of LVAD, peripheral infection, and central infection, on basis of diagnosis on ${ }^{18} \mathrm{~F}$-FDG PET/CT. There was significantly higher mortality in ${ }^{18} \mathrm{~F}-$ FDG-avid central vs. peripheral infection group. No uninfected patients died $(P<0.03$, log-rank test). (Reproduced from (21).) 
TABLE 1

Comparison of Anatomic and Functional Imaging Modalities for Imaging Cardiovascular Device Infection

\begin{tabular}{|c|c|c|}
\hline Modality & Pros & Cons \\
\hline \multirow[t]{4}{*}{ TEE/TTE } & Provides first-line imaging for infective endocarditis & Shadows artifacts/misses lesions \\
\hline & Detects vegetation and perivalvular complications & $\begin{array}{l}\text { Cannot differentiate infectious from } \\
\text { noninfected vegetation }\end{array}$ \\
\hline & Assesses valvular function & $\begin{array}{l}\text { Cannot evaluate right-side heart and chest } \\
\text { wall CIED pocket and leads }\end{array}$ \\
\hline & Predicts embolic risk & \\
\hline \multirow[t]{4}{*}{ Cardiac CT } & Provides first-line imaging for infective endocarditis & Has metallic artifacts, nonspecific findings \\
\hline & Detects large vegetation & Is less sensitive for small vegetation \\
\hline & Is better than TEE for perivalvular complication evaluation & Is not for extrathoracic evaluation \\
\hline & Detects chest wall CIED infection & \\
\hline \multirow[t]{4}{*}{${ }^{18}$ F-FDG PET/CT } & Has high imaging sensitivity & Provides false-positive findings for inflammation \\
\hline & Provides earlier diagnosis & Is less sensitive for small vegetation \\
\hline & Assesses extracardiac infection & \\
\hline & Provides a signal of host immune response & \\
\hline \multirow[t]{2}{*}{ WBC scan } & Has high specificity & Has moderate sensitivity \\
\hline & Assesses extracardiac infection & Is labor-intensive \\
\hline
\end{tabular}

Enterobacteriaceae (34). In addition, ${ }^{18} \mathrm{~F}$-trehalose might be a specific tracer for mycobacteria-specific imaging (35).

In summary, whereas maltodextrin-based tracers such as ${ }^{18} \mathrm{~F}-$ maltohexaose and ${ }^{18} \mathrm{~F}$-maltotriose are promising for bacterial infection imaging, published studies thus far are limited to experimental animal models, and translational clinical data are lacking. More studies are needed to address issues such as tracer stability in the blood and, more importantly, the pharmacokinetics of the tracers, before they are applied in human subjects.

Nucleoside. Fialuridine-5-iodouracil (FIAU) is an analog of a nucleoside substrate for bacterial thymidine kinase but is not phosphorylated by the human kinase (37). ${ }^{124}$ I labeled FIAU ( ${ }^{124}$ I-
FIAU) has proven capable of visualizing infection in mice induced by a wild-type strain of $E$. coli, but not by a thymidine kinasedeficient mutant strain, indicating its bacterial thymidine kinase specificity (37). However, not all bacteria have an FIAU-binding thymidine kinase. For example, $P$. aeruginosa and Nocardia species do not take up FIAU because of lack of the kinase (38), thus limiting the use of ${ }^{124}$ I-FIAU for imaging a broad bacterial infection. A preclinical human study with ${ }^{124}$ I-FIAU for assessing prosthetic joint infection showed that the tracer lacks specificity, likely related to host mitochondrial thymidine kinase metabolism (39), leading to a high background activity, particularly muscle uptake, and limiting its use clinically.

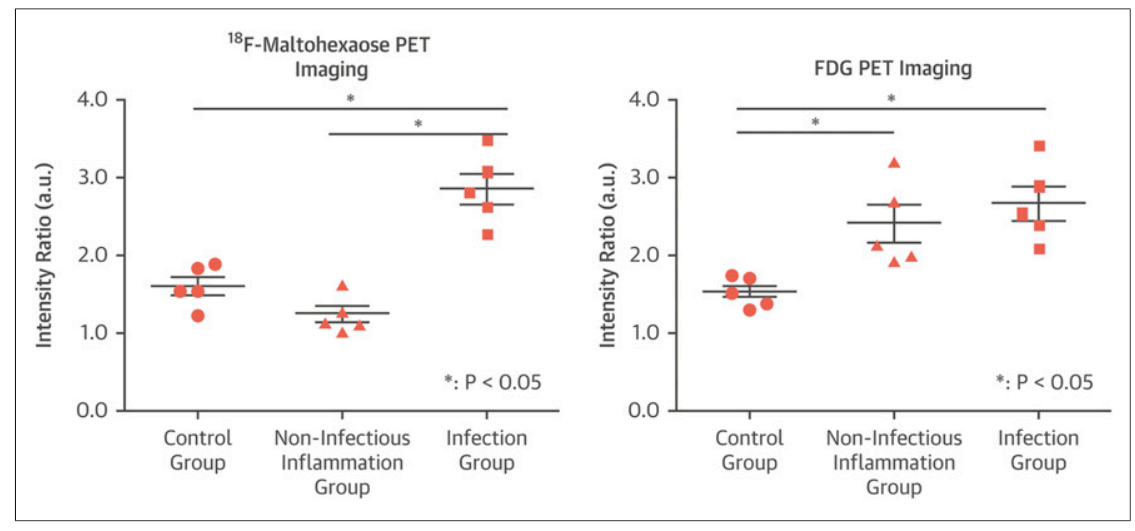

FIGURE 3. ${ }^{18} \mathrm{~F}$-maltohexaose PET and ${ }^{18} \mathrm{~F}$-FDG PET in mouse infection models. On ${ }^{18} \mathrm{~F}-$ maltohexaose PET scan, infection mice showed significant increase in tracer intensity compared with control and noninfectious inflammation mice. In contrast, with ${ }^{18} \mathrm{~F}-\mathrm{FDG}$ PET imaging, both infection and noninfectious inflammation groups had similar significant increases in intensity compared with control group, demonstrating lack of specificity. a.u. = arbitrary units. (Reproduced from (36).)

\section{Antibiotics}

Antibiotics have been radiolabeled for their potential use in bacterial infection imaging given their specific binding and uptake in bacteria. Among the different groups of radiolabeled antibiotics that have been tested for almost 2 decades (40), ${ }^{99 \mathrm{~m}} \mathrm{Tc}$-labeled ciprofloxacin is the most extensively studied and has been assessed in large clinical trials for use in bacterial infection imaging. Ciprofloxacin is an analog of quinolone, a broad-spectrum antibiotic that inhibits bacterial DNA synthesis by binding to bacterial DNA gyrase. An early clinical study showed that compared with radiolabeled WBC scanning, ${ }^{99 m}$ Tc-ciprofloxacin was the preferred imaging tracer for infection, but it had a fairly high falsenegative rate (41). A later large multicenter clinical trial showed that ${ }^{99 \mathrm{~m}} \mathrm{Tc}$-ciprofloxacin 
had a compromised specificity likely caused by its accumulation in noninfectious inflammation sites (42). Ciprofloxacin was also labeled with ${ }^{18} \mathrm{~F}$ for PET imaging (43), and a study showed that although increased activity was detected in infected tissue, it was subsequently washed out, likely representing increased regional blood flow and vascular permeability instead of specific ciprofloxacin binding to bacteria (43). In addition, emerging bacterial resistance to ciprofloxacin was also a concern because it can lead to false-negative imaging results (44). Besides ciprofloxacin, many other groups of antibiotics have been labeled and tested (40). Unfortunately, no single radiolabeled antibiotic tracer has been shown to be highly specific for bacterial infections. Thus, although radiolabeled antibiotics, particularly ${ }^{99} \mathrm{~m}$ Tc- or ${ }^{18} \mathrm{~F}$-labeled ciprofloxacin, have been extensively studied in both experimental animals and human subjects, they are not used clinically because of their nonspecificity and low sensitivity. In addition, there is no report regarding radiolabeled antibiotics for imaging cardiovascular device infection in either animal models or human subjects.

\section{Antimicrobial Peptides}

To overcome the nonspecificity and bacterial resistance of radiolabeled antibiotics, some antimicrobial peptides have been radiolabeled for their potential use in specific bacterial infection imaging. For example, a synthetic peptide, ubiquicidin 29-41, was radiolabeled and studied for use in bacterial infection imaging. Animal studies showed that ${ }^{99 m}$ Tc-ubiquicidin 29-41 accumulated in bacterial infection sites but not in sterile inflammation sites (45). However, small clinical trials showed a variable specificity of $80 \%-100 \%(46,47)$. Binding of ubiquicidin to bacteria is initiated and mediated by its positive charges, which interact with negatively charged phospholipids in the bacterial walls (48). This mechanism raises concern about ubiquicidin-bacterial binding strength and mechanistic specificity. In addition, ubiquicidin also binds to fungi, and thus ${ }^{99 \mathrm{~m}} \mathrm{Tc}$-ubiquicidin 29-41 may not be able to differentiate bacterial infection from fungal infection (49). ${ }^{68} \mathrm{Ga}$-labeled ubiquicidin $29-41$ was also developed for PET imaging and showed similar findings (50). Like radiolabeled antibiotics, radiolabeled antibacterial peptides are less likely to be clinically translatable.

\section{Bacterial Antibodies}

Radiolabeled antibodies are one of the first approaches applied for bacterial infection imaging. Early animal studies using radiolabeled $\left({ }^{111} \mathrm{In}\right.$ and $\left.{ }^{99} \mathrm{~m} \mathrm{Tc}\right)$ human immunoglobulin showed that although much higher activity was seen in infection sites, less activity was observed in inflammation sites, likely because of increased vascular permeability and nonspecific Fc fragment binding to immune cells recruited to the site of infection (51). To overcome the nonspecific binding related to $\mathrm{Fc}$ region, radiolabeled antibody fragments lacking the $\mathrm{Fc}$ region, such as $\mathrm{Fab}^{\prime}$ fragment, were designed, without success (51). As an alternative, antigen-specific monoclonal antibodies were tested (52), but monoclonal antibodies would target only a specific strain or species of bacteria with the same antigen and thus would have only limited use for detecting broad bacterial infections. In addition to the nonspecificity, radiolabeled antibodies are well known for slow blood-pool clearance and poor imaging quality, making them less likely to be useful for the rapid diagnosis of infection that is critical for immediate clinical management. Thus, although different approaches have been attempted, none of the antibodybased tracers has shown desirable radio-pharmacokinetic features for diagnosis of infection.

\section{Bacteriophages and Bacterial DNA/RNA Hybrid Nucleotide Oligomers}

Other tracers that have been tested for bacteria-specific infection imaging include ${ }^{99 \mathrm{~m}} \mathrm{Tc}$-labeled bacteriophages (53), which are viruses that specifically infect bacteria but not mammalian cells, and radiolabeled bacterial DNA/RNA hybrid nucleotide oligomers that specifically target the bacterial DNA or RNA in the pathogens $(54,55)$. These could be attractive tracers for specific bacterial imaging at least in theory; however, studies are in their early stages.

\section{CONSIDERATIONS OF ${ }^{18}$ F-FDG AND BACTERIA-TARGETING TRACERS FOR INFECTION IMAGING}

Given the tremendous clinical impact, it is imperative to develop an imaging tool for rapid and accurate diagnosis of cardiovascular device infection with high sensitivity and specificity. ${ }^{18} \mathrm{~F}-\mathrm{FDG}$ $\mathrm{PET} / \mathrm{CT}$ has unique merits over anatomic imaging techniques for earlier and more sensitive diagnosis of cardiovascular device infection. In addition, ${ }^{18}$ F-FDG PET/CT can identify extracardiac infection sources or infectious emboli, which are critical for patient management. Thus, ${ }^{18}$ F-FDG PET/CT has been recommended by the European Society for Cardiology for the diagnosis of cardiac device-related and prosthetic valve endocarditis (7). Although ${ }^{18} \mathrm{~F}-$ FDG is criticized for its nonspecific accumulation in inflammation sites $(56,57)$, differentiation between infection and inflammation can be reasonably achieved by recognizing the ${ }^{18} \mathrm{~F}-\mathrm{FDG}$ uptake pattern: ${ }^{18} \mathrm{~F}-\mathrm{FDG}$ uptake in an infection site is generally heterogeneous, with focal increased activity, whereas the distribution of ${ }^{18} \mathrm{~F}$ FDG in an inflammatory area is more homogeneous and mild $(58,59)$. In addition, clinical information such as about the device material (metal or bioprosthesis) and surgical technique (use of adhesion glue or anticalcification material) is also useful for the differentiation. For example, like application of surgical adhesive to a mechanical prosthesis (60), application of anticalcification treatment with $\alpha$-amino oleic acid to a bioprosthetic tissue can cause a characteristic pattern of ${ }^{18}$ F-FDG uptake: low shortly after surgery but intensely homogeneous at 6 mo and persisting up to $1 \mathrm{y}$ or even longer (61). A recent study showed that the diagnostic accuracy of ${ }^{18}$ F-FDG PET/CT for prosthetic endocarditis can be significantly improved after adjusting clinical cofounders (62). If infection and inflammation can be reasonably differentiated on the basis of ${ }^{18}$ F-FDG uptake pattern and surgical information, then the nonspecific ${ }^{18} \mathrm{~F}$-FDG uptake may actually represent a unique feature of ${ }^{18} \mathrm{~F}-\mathrm{FDG}$ for infection diagnosis: its high sensitivity for infection with a low rate of missing an infection (low false-negative rate).

${ }^{18}$ F-FDG signal in an infection site represents the overall hostpathogen immune response and thus the underlying severity of infection. In addition, the ${ }^{18} \mathrm{~F}-\mathrm{FDG}$ uptake and distribution pattern in the liver, spleen, and bone marrow seen on whole-body scans provides information on the activation status of the reticuloendothelial system, representing the body's systemic response to the infection. Thus, findings on ${ }^{18} \mathrm{~F}-\mathrm{FDG}$ PET/CT represent the severity of the infection and the body's overall immune response, which are more critical for decisions on patient management than on the accuracy for diagnosis per se (63). ${ }^{18} \mathrm{~F}$-FDG PET/CT findings thus may in fact be more reliable in guiding patient management and predicting outcome. A negative ${ }^{18}$ F-FDG PET/CT finding, which represents either no infection (true-negative) or mild infection (but false-negative based on standard diagnosis), may warrant conservative antibiotic treatment without device extraction. A positive 
${ }^{18}$ F-FDG PET/CT finding (when inflammation is excluded on the basis of uptake pattern and surgical history) confirms infection and necessitates complete device extraction. In other words, ${ }^{18} \mathrm{~F}-\mathrm{FDG}$ PET/CT may have the potential to quantify the severity of infection and accordingly guide patient management beyond its capacity in cardiac device infection diagnosis. This hypothesis is supported by several prior studies, though with small numbers of patients $(64,65)$.

On the other hand, bacteria-targeting tracers detect only the specific bacteria itself, without providing information on the severity of the infection and the body's immune response to it. Although the primary goal of developing bacteria-imaging tracers is to provide a specific diagnosis of infection, unexpectedly, many of these assumed bacteria-specific tracers also show nonspecific accumulation in inflammation sites with undesirable radio-pharmacokinetic features for infection imaging. There are also additional limitations associated with each group of the tracers.

Antibiotics and antimicrobial peptides kill or inhibit bacteria at a low concentration. Thus, antibiotics and antimicrobial peptide-based tracers lack signal amplification with low intrabacterial accumulation, limiting their signal sensitivity. Although their binding to bacteria is specific, these tracers also show activity in inflammation sites due to increased vascular permeability and decreased washout (43). Preantibiotic treatment could also significantly decrease bacterial viability and loading, further decreasing the sensitivity (41). Finally, bacterial antibiotic resistance can potentially lead to a false-negative findings (44). Thus, these tracers have not made — and are not expected to make- their final inauguration in the clinic for specific bacterial infection imaging.
Antibody-based tracers are studied mainly in oncology imaging. Radiolabeled antibodies suffer from low target accumulation, nonspecific binding (related to Fc segment), high blood-pool retention due to slow excretion, and poor imaging quality. The same issues exist in radiolabeled bacterial antibodies for infection imaging $(51,52)$.

Bacterial thymidine kinase targeting FIAU can also be phosphorylated by mammalian cell mitochondrial kinase, raising concerns about nonspecificity and being less likely to be clinically translatable $(38,39)$. Tracers based on bacteriophages and bacterial DNA/RNA hybrid nucleotide oligomers are in their early stages of development and are conceptually attractive $(53,55)$.

Unlike the above-mentioned types of tracers, uptake of the maltodextrin tracers is actively mediated by the bacterial maltodextrin transporter, similarly to ${ }^{18} \mathrm{~F}-\mathrm{FDG}$, which is mediated by the glucose transporter. Maltodextrin tracers can reach high intrabacterial activity because there is continuous internalization through the transporters, facilitating highly sensitive detection (29). Meanwhile, there is efficient and rapid renal excretion of some of the maltodextrin tracers, such as ${ }^{18} \mathrm{~F}$-maltotriose (33). However, not all maltodextrin transporter-targeting tracers show efficient excretion and ideal radiopharmacokinetic features. For example, ${ }^{18} \mathrm{~F}$-maltose is excreted mainly by the hepatobiliary pathway, with minimal renal excretion, making it an undesired tracer for infection imaging (32). Among the current reported maltodextrin transporter-targeting tracers, ${ }^{18} \mathrm{~F}$-maltotriose holds the most promise for clinical translation based on an animal study (33). However, different from ${ }^{18} \mathrm{~F}-\mathrm{FDG}$, which is trapped inside the cell as FDG-6-P, the metabolism of ${ }^{18} \mathrm{~F}$-maltotriose inside the

TABLE 2

Comparison of ${ }^{18} \mathrm{~F}-\mathrm{FDG}$ and Bacteria-Targeting Tracers

\begin{tabular}{|c|c|c|c|c|}
\hline \multirow[b]{2}{*}{ Tracer } & \multirow[b]{2}{*}{ Target } & \multicolumn{2}{|c|}{ Studies on... } & \multirow[b]{2}{*}{ Main findings } \\
\hline & & Animals & Humans & \\
\hline${ }^{18} \mathrm{~F}-\mathrm{FDG}$ & Glut & $\mathrm{Y}$ & $\mathrm{Y}$ & $\begin{array}{l}\text { Early and sensitive diagnosis of infection in } \\
\text { cardiac and extracardiac portions; may } \\
\text { guide management based on severity }\end{array}$ \\
\hline \multicolumn{5}{|l|}{ MDT targeting tracers } \\
\hline${ }^{18} \mathrm{~F}$-maltotriose & MDT & Y & $\mathrm{N}$ & $\begin{array}{l}\text { Tested on rat cardiac device infection model; } \\
\text { differentiates infection from inflammation }\end{array}$ \\
\hline${ }^{18} \mathrm{~F}$-maltohexaose & MDT & $\mathrm{Y}$ & $\mathrm{N}$ & $\begin{array}{l}\text { Tested on mouse muscle infection model; } \\
\text { differentiates infection from inflammation }\end{array}$ \\
\hline${ }^{18} \mathrm{~F}$-maltose & MDT & $\mathrm{Y}$ & $\mathrm{N}$ & Suboptimal radiopharmaceutics in mice \\
\hline${ }^{18} \mathrm{~F}$-trehalose & MDT & $\mathrm{Y}$ & $\mathrm{N}$ & Limited to mycobacteria \\
\hline${ }^{18} \mathrm{~F}$-sorbitol & MDT & Y & $\mathrm{N}$ & Limited to gram-negative bacteria \\
\hline 124I-FIAU & TK & $\mathrm{Y}$ & $\mathrm{Y}$ & $\begin{array}{l}\text { Nonspecific uptake in inflammation; not } \\
\text { clinically translated }\end{array}$ \\
\hline Antibiotics (99mTc-ciprofloxacin) & DNA gyrase & Y & $\mathrm{Y}$ & $\begin{array}{l}\text { Low sensitivity, nonspecific uptake; not } \\
\text { clinically translated }\end{array}$ \\
\hline $\begin{array}{l}\text { Antimicrobial peptides } \\
\text { (99mTc-UBI29-41) }\end{array}$ & Innate immune & Y & $\mathrm{Y}$ & $\begin{array}{l}\text { Low sensitivity, nonspecific uptake; not } \\
\text { clinically translated }\end{array}$ \\
\hline Antibodies & Antigen & Y & $\mathrm{Y}$ & $\begin{array}{l}\text { Slow blood pool clearance; nonspecific uptake, } \\
\text { poor imaging quality; not clinically translated }\end{array}$ \\
\hline
\end{tabular}

Glut = glucose transporter; MDT = maltodextrin transporter; TK = thymidine kinase. 
bacteria is unknown. It remains unclear whether ${ }^{18} \mathrm{~F}$ is trapped inside the bacteria or whether it will efflux or diffuse out of the cell after ${ }^{18} \mathrm{~F}$-maltotriose degradation. In addition, its stability in the blood is unknown either. More studies are needed to explore its potential for clinical translation. Table 2 summarizes and compares the main findings of ${ }^{18} \mathrm{~F}$-FDG and other bacteria-targeting tracers.

\section{TECHNICAL CHALLEGNES FOR BACTERIA-TARGETING PET TRACERS}

In addition to the inherent limitations of the bacteria-targeting tracers, other challenges for direct PET imaging of infection with these tracers include the complex clinical setting of infection (including empiric antibiotic treatment and biofilm formation) and the technical capability of the current PET camera for detecting small lesions or lesions with low counts. Empiric antibiotic therapy is generally started for any case of suspected cardiac device infection before a definite diagnosis is made. The treatment may greatly decrease bacterial signal, much more significantly than the host immune response signal as revealed by ${ }^{18}$ F-FDG. In addition, cardiac device infection is frequently associated with biofilm formation, which limits permeation of tracers such as antibiotics and antibodies (66). Although preliminary animal work showed that ${ }^{18} \mathrm{~F}$-maltotriose could potentially penetrate the biofilm (33), detailed work is lacking. Most of the current PET camera may not be able to detect a small lesions with low counts given the limited spatial resolution. In addition, these tracers cannot access intracellular bacteria when they are phagocytosed by immune cells. Cardiac and respiratory motion during data acquisition would impose a further technical challenge. These issues need to be addressed when these bacteria-targeting tracers are being translated to the clinic (67).

\section{CONCLUSION}

Direct bacteria-targeted tracers have been assumed to be more specific than ${ }^{18} \mathrm{~F}-\mathrm{FDG}$ for imaging bacterial infection. However, it turns out that most of the bacteria-targeted tracers also show nonspecific accumulation at inflammation sites. Moreover, most of the bacterial tracers suffer from low sensitivity due to no intrabacterial signal amplification, prior antibiotic treatment, and the impermeability of biofilm. One exception could be maltodextrin-based tracers such as ${ }^{18} \mathrm{~F}$-maltotriose, which shows specificity for bacteria with high sensitivity due to signal amplification from continuous intrabacterial accumulation by the maltodextrin transporter. However, current data are limited to early experimental studies on animals, and it is unclear whether successful translation into the clinic will be possible. On the other hand, ${ }^{18} \mathrm{~F}-\mathrm{FDG}$ PET/CT is sensitive for early diagnosis of infection, and ${ }^{18} \mathrm{~F}-\mathrm{FDG}$ findings represent the overall severity of infection and the body's immune response to the infection-capabilities that are more reliable for making decisions on patient management. Accumulating clinical data support the use of ${ }^{18}$ F-FDG PET/CT for imaging cardiovascular device infections.

\section{REFERENCES}

1. Greenspon AJ, Patel JD, Lau E, et al. 16-year trends in the infection burden for pacemakers and implantable cardioverter-defibrillators in the United States: 1993 to 2008. J Am Coll Cardiol. 2011;58:1001-1006.

2. Tan EM, DeSimone DC, Sohail MR, et al. Outcomes in patients with cardiovascular implantable electronic device infection managed with chronic antibiotic suppression. Clin Infect Dis. 2017;64;1516-1521.

3. Mond HG, Proclemer A. The 11th world survey of cardiac pacing and implantable cardioverter-defibrillators: calendar year 2009-a World Society of Arrhythmia's project. Pacing Clin Electrophysiol. 2011;34:1013-1027.
4. Tarakji KG, Chan EJ, Cantillon DJ, et al. Cardiac implantable electronic device infections: presentation, management, and patient outcomes. Heart Rhythm. 2010; 7:1043-1047.

5. Erba PA, Pizzi MN, Roque A, et al. Multimodality imaging in infective endocarditis: an imaging team within the endocarditis team. Circulation. 2019;140:17531765 .

6. Nishimura RA, Otto CM, Bonow RO, et al. 2014 AHA/ACC guideline for the management of patients with valvular heart disease: executive summary-a report of the American College of Cardiology/American Heart Association Task Force on Practice Guidelines. Circulation. 2014;129:2440-2492.

7. Habib G, Lancellotti P, Antunes MJ, et al. 2015 ESC guidelines for the management of infective endocarditis: the Task Force for the Management of Infective Endocarditis of the European Society of Cardiology (ESC). Endorsed by: European Association for Cardio-Thoracic Surgery (EACTS), the European Association of Nuclear Medicine (EANM). Eur Heart J. 2015;36:3075-3128.

8. Habib G, Erba PA, Iung B, et al. Clinical presentation, aetiology and outcome of infective endocarditis: results of the ESC-EORP EURO-ENDO (European Infective Endocarditis) Registry—a prospective cohort study. Eur Heart J. 2019;40: 3222-3232.

9. Habib G, Badano L, Tribouilloy C, et al. Recommendations for the practice of echocardiography in infective endocarditis. Eur J Echocardiogr. 2010;11:202-219.

10. Di Salvo G, Habib G, Pergola V, et al. Echocardiography predicts embolic events in infective endocarditis. J Am Coll Cardiol. 2001;37:1069-1076.

11. Hill EE, Herijgers P, Claus P, Vanderschueren S, Peetermans WE, Herregods MC. Abscess in infective endocarditis: the value of transesophageal echocardiography and outcome: a 5-year study. Am Heart J. 2007;154:923-928.

12. Grob A, Thuny F, Villacampa C, et al. Cardiac multidetector computed tomography in infective endocarditis: a pictorial essay. Insights Imaging. 2014;5:559570 .

13. Chen W, Kim J, Molchanova-Cook OP, Dilsizian V. The potential of FDG PET/ CT for early diagnosis of cardiac device and prosthetic valve infection before morphologic damages ensue. Curr Cardiol Rep. 2014;16:459.

14. Chen W, Sajadi MM, Dilsizian V. Merits of FDG PET/CT and functional molecular imaging over anatomic imaging with echocardiography and CT angiography for the diagnosis of cardiac device infections. JACC Cardiovasc Imaging. 2018;11:1679-1691.

15. Gomes A, Glaudemans AWJM, Touw DJ, et al. Diagnostic value of imaging in infective endocarditis: a systematic review. Lancet Infect Dis. 2017;17:e1-e14.

16. Juneau D, Golfam M, Hazra S, et al. Positron emission tomography and singlephoton emission computed tomography imaging in the diagnosis of cardiac implantable electronic device infection: a systematic review and meta-analysis. Circ Cardiovasc Imaging. 2017;10:e005772.

17. Saby L, Laas O, Habib G, et al. Positron emission tomography/computed tomography for diagnosis of prosthetic valve endocarditis: increased valvular ${ }^{18}$ F-fluorodeoxyglucose uptake as a novel major criterion. J Am Coll Cardiol. 2013; 61:2374-2382.

18. Pizzi MN, Roque A, Fernández-Hidalgo N, et al. Improving the diagnosis of infective endocarditis in prosthetic valves and intracardiac devices with ${ }^{18} \mathrm{~F}$ fluordeoxyglucose positron emission tomography/computed tomography angiography: initial results at an infective endocarditis referral center. Circulation. 2015; 132:1113-1126.

19. Orvin K, Goldberg E, Bernstine H, et al. The role of FDG-PET/CT imaging in early detection of extra-cardiac complications of infective endocarditis. Clin Microbiol Infect. 2015;21:69-76.

20. Kim J, Feller ED, Chen W, Dilsizian V. FDG PET/CT imaging for LVAD associated infections. JACC Cardiovasc Imaging. 2014;7:839-842.

21. Kim J, Feller ED, Chen W, Liang Y, Dilsizian V. FDG PET/CT for early detection and localization of left ventricular assist device infection: impact on patient management and outcome. JACC Cardiovasc Imaging. 2019;12:722-729.

22. Rouzet F, Chequer R, Benali K, et al. Respective performance of ${ }^{18} \mathrm{~F}$-FDG PET and radiolabeled leukocyte scintigraphy for the diagnosis of prosthetic valve endocarditis. J Nucl Med. 2014;55:1980-1985.

23. Lancellotti P, Habib G, Oury C, Nchimi A. Positron emission tomography/computed tomography imaging in device infective endocarditis: ready for prime time. Circulation. 2015;132:1076-1080.

24. Chen W, Dilsizian V. FDG PET/CT for the diagnosis and management of infective endocarditis: expert consensus vs evidence-based practice. J Nucl Cardiol. 2019;26:313-315.

25. Dilsizian V, Achenbach S, Narula J. Adding or selecting imaging modalities for incremental diagnosis: a case study of ${ }^{18} \mathrm{FDG}$ PET/CT in prosthetic valve endocarditis. JACC Cardiovasc Imaging. 2013;6:1020-1021.

26. Boos W, Shuman H. Maltose/maltodextrin system of Escherichia coli: transport, metabolism, and regulation. Microbiol Mol Biol Rev. 1998;62:204-229. 
27. Ferenci T. The recognition of maltodextrins by Escherichia coli. Eur J Biochem. 1980;108:631-636.

28. Oldham ML, Chen S, Chen J. Structural basis for substrate specificity in the Escherichia coli maltose transport system. Proc Natl Acad Sci USA. 2013;110: 18132-18137.

29. Axer A, Hermann S, Kehr G, et al. Harnessing the maltodextrin transport mechanism for targeted bacterial imaging: structural requirements for improved in vivo stability in tracer design. ChemMedChem. 2018;13:241-250.

30. Ning X, Lee S, Wang Z, et al. Maltodextrin-based imaging probes detect bacteria in vivo with high sensitivity and specificity. Nat Mater. 2011;10:602-607.

31. Ning X, Seo W, Lee S, et al. PET imaging of bacterial infections with fluorine18-labeled maltohexaose. Angew Chem Int Ed Engl. 2014;53:14096-14101.

32. Gowrishankar G, Namavari M, Jouannot EB, et al. Investigation of 6-[ $\left.{ }^{18} \mathrm{~F}\right]-$ fluoromaltose as a novel PET tracer for imaging bacterial infection. PLoS One. 2014;9:e107951.

33. Gowrishankar G, Hardy J, Wardak M, et al. Specific imaging of bacterial infection Using 6" ${ }^{18} \mathrm{~F}$-fluoromaltotriose: a second-generation PET tracer targeting the maltodextrin transporter in bacteria. J Nucl Med. 2017;58:1679-1684.

34. Weinstein EA, Ordonez AA, DeMarco VP, et al. Imaging Enterobacteriaceae infection in vivo with ${ }^{18} \mathrm{~F}$-fluorodeoxysorbitol positron emission tomography. Sci Transl Med. 2014;6:259ra146.

35. Rundell SR, Wagar ZL, Meints LM, et al. Deoxyfluoro-d-trehalose (FDTre) analogues as potential PET probes for imaging mycobacterial infection. Org Biomol Chem. 2016;14:8598-8609.

36. Takemiya K, Ning X, Seo W, et al. Novel PET and near infrared imaging probes for the specific detection of bacterial infections associated with cardiac devices. JACC Cardiovasc Imaging. 2019;12:875-886.

37. Bettegowda C, Foss CA, Cheong I, et al. Imaging bacterial infections with radiolabeled 1-(2'-deoxy-2'-fluoro-beta-D-arabinofuranosyl)-5-iodouracil. Proc Natl Acad Sci USA. 2005;102:1145-1150.

38. Peterson KL, Reid WC, Freeman AF, et al. The use of ${ }^{14} \mathrm{C}-\mathrm{FIAU}$ to predict bacterial thymidine kinase presence: implications for radiolabeled FIAU bacterial imaging. Nucl Med Biol. 2013;40:638-642.

39. Zhang XM, Zhang HH, McLeroth P, et al. [ $\left.{ }^{124} \mathrm{I}\right] \mathrm{FIAU}$ : Human dosimetry and infection imaging in patients with suspected prosthetic joint infection. Nucl Med Biol. 2016;43:273-279.

40. van Oosten M, Hahn M, Crane LM, et al. Targeted imaging of bacterial infections: advances, hurdles and hopes. FEMS Microbiol Rev. 2015;39:892-916.

41. Vinjamuri S, Hall AV, Solanki KK, et al. Comparison of ${ }^{99 \mathrm{~m}} \mathrm{Tc}$ infection imaging with radiolabelled white-cell imaging in the evaluation of bacterial infection. Lancet. 1996;347:233-235.

42. Britton KE, Wareham DW, Das SS, et al. Imaging bacterial infection with ${ }^{99 \mathrm{~m}} \mathrm{Tc}-$ ciprofloxacin (Infecton). J Clin Pathol. 2002;55:817-823.

43. Langer $\mathrm{O}$, Brunner $\mathrm{M}$, Zeitlinger $\mathrm{M}$, et al. In vitro and in vivo evaluation of $\left[{ }^{18} \mathrm{~F}\right]$ ciprofloxacin for the imaging of bacterial infections with PET. Eur J Nucl Med Mol Imaging. 2005;32:143-150.

44. Ebenhan T, Lazzeri E, Gheysens O. Imaging of bacteria: is there any hope for the future based on past experience? Curr Pharm Des. 2018;24:772-786.

45. Welling MM, Mongera S, Lupetti A, et al. Radiochemical and biological characteristics of ${ }^{99 \mathrm{~m}} \mathrm{Tc}-\mathrm{UBI} 29-41$ for imaging of bacterial infections. Nucl Med Biol. 2002;29:413-422.

46. Akhtar MS, Qaisar A, Irfanullah J, et al. Antimicrobial peptide ${ }^{99 \mathrm{~m}} \mathrm{Tc}$-ubiquicidin 29-41 as human infection-imaging agent: clinical trial. J Nucl Med. 2005;46:567-573.

47. Gandomkar M, Najafi R, Shafiei M, et al. Clinical evaluation of antimicrobial peptide $\left[{ }^{99 \mathrm{~m}} \mathrm{Tc} /\right.$ Tricine/HYNIC $\left.{ }^{0}\right]$ ubiquicidin $29-41$ as a human-specific infection imaging agent. Nucl Med Biol. 2009;36:199-205.

48. Ferro-Flores G, Arteaga de Murphy C, Pedraza-López M, et al. In vitro and in vivo assessment of ${ }^{99 \mathrm{~m} T c-U B I}$ specificity for bacteria. Nucl Med Biol. 2003;30: 597-603.
49. Lupetti A, de Boer MG, Erba P, Campa M, Nibbering PH. Radiotracers for fungal infection imaging. Med Mycol. 2011;49(suppl 1):S62-S69.

50. Ebenhan T, Zeevaart JR, Venter JD, et al. Preclinical evaluation of ${ }^{68} \mathrm{Ga}$-labeled 1,4,7-triazacyclononane-1,4,7-triacetic acid-ubiquicidin as a radioligand for PET infection imaging. J Nucl Med. 2014;55:308-314.

51. Fischman AJ, Rubin RH, White JA, et al. Localization of Fc and Fab fragments of nonspecific polyclonal IgG at focal sites of inflammation. J Nucl Med. 1990; 31:1199-1205.

52. Rubin RH, Young LS, Hansen WP, et al. Specific and nonspecific imaging of localized Fisher immunotype 1 Pseudomonas aeruginosa infection with radiolabeled monoclonal antibody. J Nucl Med. 1988;29:651-656.

53. Rusckowski M, Gupta S, Liu G, Dou S, Hnatowich DJ. Investigations of a ${ }^{99 m}$ Tclabeled bacteriophage as a potential infection-specific imaging agent. J Nucl Med. 2004;45:1201-1208.

54. Chen L, Wang Y, Cheng D, et al. ${ }^{99 \mathrm{~m}} \mathrm{Tc}-\mathrm{MORF}$ oligomers specific for bacterial ribosomal RNA as potential specific infection imaging agents. Bioorg Med Chem. 2013;21:6523-6530.

55. Wang Y, Chen L, Liu X, et al. Detection of Aspergillus fumigatus pulmonary fungal infections in mice with ${ }^{99 \mathrm{~m}} \mathrm{Tc}$-labeled MORF oligomers targeting ribosomal RNA. Nucl Med Biol. 2013;40:89-96.

56. Chen W, Dilsizian V. Targeted PET/CT imaging of vulnerable atherosclerotic plaques: microcalcification with sodium fluoride and inflammation with fluorodeoxyglucose. Curr Cardiol Rep. 2013;15:364.

57. Chen W, Dilsizian V. ${ }^{18} \mathrm{~F}$-fluorodeoxyglucose PET imaging of coronary atherosclerosis and plaque inflammation. Curr Cardiol Rep. 2010;12:179-184.

58. Mathieu C, Mikail N, Benali K, et al. Characterization of ${ }^{18} \mathrm{~F}$-fluorodeoxyglucose uptake pattern in noninfected prosthetic heart valves. Circ Cardiovasc Imaging. 2017;10:e005585.

59. Roque A, Pizzi MN, Fernández-Hidalgo N, et al. Morpho-metabolic post-surgical patterns of non-infected prosthetic heart valves by $\left[{ }^{18} \mathrm{~F}\right] \mathrm{FDG}$ PET/CTA: "normality" is a possible diagnosis. Eur Heart J Cardiovasc Imaging. 2020;21: 24-33.

60. Scholtens AM, Swart LE, Verberne HJ, et al. Confounders in FDG-PET/CT imaging of suspected prosthetic valve endocarditis. JACC Cardiovasc Imaging. 2016;9:1462-1465.

61. Roque A, Pizzi MN, Fernández-Hidalgo N, et al. Mosaic bioprostheses may mimic infective endocarditis by PET/CTA: trust the uptake pattern to avoid misdiagnosis. JACC Cardiovasc Imaging. January 9, 2020 [Epub ahead of print].

62. Swart LE, Gomes A, Scholtens AM, et al. Improving the diagnostic performance of ${ }^{18} \mathrm{~F}$-fluorodeoxyglucose positron-emission tomography/computed tomography in prosthetic heart valve endocarditis. Circulation. 2018;138:1412-1427.

63. Chen W, Dilsizian V. Is ${ }^{18} \mathrm{~F}$-flurodeoxyglucose positron emission tomography/ computed tomography more reliable than clinical standard diagnosis for guiding patient management decisions in cardiac implantable electronic device infection? Circ Cardiovasc Imaging. 2019;12:e009453.

64. Ploux S, Riviere A, Amraoui S, et al. Positron emission tomography in patients with suspected pacing system infections may play a critical role in difficult cases. Heart Rhythm. 2011;8:1478-1481.

65. Calais J, Touati A, Grall N, et al. Diagnostic impact of ${ }^{18} \mathrm{~F}$-fluorodeoxyglucose positron emission tomography/computed tomography and white blood cell SPECT/ computed tomography in patients with suspected cardiac implantable electronic device chronic infection. Circ Cardiovasc Imaging. 2019;12:e07188.

66. Dengler Haunreiter V, Boumasmoud M, Häffner N, et al. In-host evolution of Staphylococcus epidermidis in a pacemaker-associated endocarditis resulting in increased antibiotic tolerance. Nat Commun. 2019;10:1149.

67. Sajadi MM, Chen W, Dilsizian V. Targeted bacteria-specific ${ }^{18} \mathrm{~F}$-fluoro-maltohexaose but not FDG PET distinguishes infection from inflammation. JACC Cardiovasc Imaging. 2019;12:887-889. 